\title{
Relationship between pancreatic vesicular monoamine transporter 2 (VMAT2) and insulin expression in human pancreas
}

\author{
Yoshifumi Saisho $\cdot$ Paul E. Harris · \\ Alexandra E. Butler · Ryan Galasso · \\ Tatyana Gurlo $\cdot$ Robert A. Rizza $\cdot$ Peter C. Butler
}

Received: 21 July 2008/ Accepted: 2 September 2008/Published online: 13 September 2008

(C) The Author(s) 2008. This article is published with open access at Springerlink.com

\begin{abstract}
Vesicular monoamine transporter 2 (VMAT2) is expressed in pancreatic beta cells and has recently been proposed as a target for measurement of beta cell mass in vivo. We questioned, (1) What proportion of beta cells express VMAT2? (2) Is VMAT2 expressed by other pancreatic endocrine or non-endocrine cells? (3) Is the relationship between VMAT2 and insulin expression disturbed in type 1 (T1DM) or type 2 diabetes (T2DM)? Human pancreas (7 non-diabetics, 5 T2DM, 10 T1DM) was immunostained for insulin, VMAT2 and other pancreatic hormones. Most beta cells expressed VMAT2. VMAT2 expression was not changed by the presence of diabetes. In tail of pancreas VMAT2 immunostaining closely correlated with insulin staining. However, VMAT2 was also expressed in some pancreatic polypeptide (PP) cells. Although VMAT2 was not excluded as a target for beta cell mass measurement, expression of VMAT2 in PP
\end{abstract}

Electronic supplementary material The online version of this article (doi:10.1007/s10735-008-9195-9) contains supplementary material, which is available to authorized users.

Y. Saisho · A. E. Butler · R. Galasso - T. Gurlo ·

P. C. Butler $(\square)$

Larry Hillblom Islet Research Center, UCLA David Geffen

School of Medicine, 900 Weyburn Place \#A,

Los Angeles, CA 90024-2852, USA

e-mail: pbutler@mednet.ucla.edu

\section{P. E. Harris}

Department of Medicine, Columbia University Medical Center, Black Building 20th floor, 650W 168th Street,

New York, NY 10032, USA

R. A. Rizza

Division of Endocrinology, Diabetes, Metabolism and Nutrition, Mayo Clinic, Rochester, MN 55905, USA cells predicts residual VMAT2 expression in human pancreas even in the absence of beta cells.

Keywords Beta cell mass .

Vesicular monoamine transporter - Type 1 diabetes .

Type 2 diabetes $\cdot$ Insulin $\cdot$ Pancreatic polypeptide

$\begin{array}{ll}\text { Abbreviations } \\ \text { T1DM } & \text { Type 1 diabetes } \\ \text { T2DM } & \text { Type 2 diabetes } \\ \text { DTBZ } & \text { Dihydrotetrabenazine } \\ \text { PET } & \text { Positron emission tomography } \\ \text { VMAT2 } & \text { Vesicular monoamine transporter 2 } \\ \text { PP } & \text { Pancreatic polypeptide } \\ \text { IRB } & \text { Institutional review board }\end{array}$

\section{Introduction}

Since both type 1 and type 2 diabetes are characterized by a deficit of beta cell mass (Butler et al. 2007, 2003; Meier et al. 2005; Ritzel et al. 2006), measurement of beta cell mass in vivo is of interest. In order to evaluate beta cell mass in vivo, a marker that can be detected by an imaging approach that is targeted to beta cells is required. One approach that has recently been applied to evaluate beta cell mass in rats in vivo makes use of uptake of the radioligand [11C]dihydrotetrabenazine (DTBZ) by the membrane protein vesicular monoamine transporter 2 (VMAT2), and its subsequent detection by positron emission tomography (PET) (Simpson et al. 2006; Souza et al. 2006). VMAT2 is expressed in the central and peripheral nervous system, the hematopoietic system and the neuroendocrine system (Anlauf et al. 2003, 2006; Eiden 2000; 
Erickson et al. 1996; Weihe and Eiden 2000; Weihe et al. 1994). VMAT2 mediates the uptake of monoamines from the cytoplasm into secretory granules in monoamine-handling cells (Eiden 2000; Erickson et al. 1996; Weihe and Eiden 2000). [11C]DTBZ is already in clinical use for PET imaging of brain in neurodegenerative disorders such as Parkinson disease (Frey et al. 2001).

In the neuroendocrine system, VMAT2 is expressed in chromaffin cells of the adrenal medulla, histamine-storing enterochromaffin-like cells of the stomach, and pancreatic islet cells (Anlauf et al. 2003; Erickson et al. 1996; Maffei et al. 2004; Simpson et al. 2006; Weihe et al. 1994). VMAT2 mRNA is more abundant in isolated islets than exocrine pancreas in humans (Maffei et al. 2004). Immunohistochemical studies in rodents and humans revealed that VMAT2 is expressed in beta cells (Anlauf et al. 2003; Simpson et al. 2006).

Based on these findings uptake of the radioligand [11C]DTBZ in pancreas detected by PET was evaluated as a method to measure beta cell mass in rats. Pancreatic [11C]DTBZ uptake was decreased in rats with streptozotocin (STZ)-induced diabetes and spontaneous type 1 diabetes (the BB-DP rat) compared to non-diabetic controls (Simpson et al. 2006; Souza et al. 2006).

Recent studies in humans with long standing type 1 diabetes also revealed decreased pancreatic [11C]DTBZ uptake compared to non-diabetic controls. However, significant [11C]DTBZ uptake was observed in the pancreas of patients with long standing type 1 diabetes (Freeby et al. 2007). This latter observation poses the question, are there other cell types in the pancreas other than beta cells that express VMAT2? Moreover is the pattern of VMAT2 expression disturbed in the setting of diabetes? We therefore studied human pancreas from non-diabetic controls, recent onset and long established type 1 diabetes and established type 2 diabetes to address the following questions. First, what proportion of pancreatic beta cells express VMAT2? Second, is VMAT2 expressed by other endocrine or non-endocrine cells in humans pancreas, and if so to what extent? Third, is the relationship between VMAT2 and insulin expression disturbed in type 1 or type 2 diabetes?

\section{Methods}

\section{Study design}

We first identified an antibody for VMAT2 with high specificity and sensitivity in humans, and established the optimal protocol for use of this antibody in human pancreas tissue. We then applied this antibody simultaneously with antibodies against either insulin, glucagon, somatostatin or pancreatic polypeptide in human pancreas to establish the specificity of VMAT2 expression to beta cells, the proportion of beta cells that express VMAT2 and to what extent these relationships are disturbed in diabetes.

Subjects and pancreatic tissue

Pancreas was obtained at autopsy at the Mayo Clinic from 21 cases and from surgery at UCLA from one case as outlined in Table 1. Autopsy cases included 7 non-diabetics, 5 with type 2 diabetes (T2DM), 6 with long standing type 1 diabetes (T1DM) and 3 with recent onset T1DM who died of diabetic ketoacidosis (see Table 1). Pancreas from one recent onset T1DM case was surgically removed (Case 13). Pancreas in the cases of long standing and recent onset T1DM cases were evaluated and included in prior reports examining beta cell turnover in T1DM (Butler et al. 2007; Meier et al. 2005, 2006). IRB approval was obtained from UCLA (surgical case) and Mayo Clinic (autopsy cases). Written informed consent was provided by the patient in whom the surgical sample was examined.

Potential autopsy cases were identified by retrospective analysis of the Mayo Clinic autopsy database. To be included, cases were required to (1) have had a full autopsy within $12 \mathrm{~h}$ of death; (2) have had a general medical examination, including at least one fasting blood glucose documented within the year before death (the exception being those with recent onset T1DM, who died at the first admission shortly after diagnosis); and (3) pancreatic tissue stored that was of adequate size and quality. Cases were excluded if (1) potential secondary causes of diabetes were present, (2) subjects had been exposed to chronic glucocorticoid treatment, or (3) pancreatic tissue had undergone autolysis or showed evidence of pancreatitis.

Tissue preparation and immunohistochemistry

At autopsy, pancreas was resected from the tail and, with a sample of spleen, fixed in formaldehyde and embedded in paraffin for subsequent analysis (with two samples of head of pancreas as per Table 1). The surgical specimen was a distal pancreatectomy, as previously described (Butler et al. 2007; Meier et al. 2006). Primary antibodies used in this study are listed in Table 2 . Sections $(4$ or $5 \mu \mathrm{m}$ ) were cut from these paraffin blocks and stained by immunofluorescence for insulin and VMAT2, using methods previously described (Meier et al. 2005, 2006). All primary antibodies with the exception of the anti-insulin antibody were incubated with the slides overnight at $4{ }^{\circ} \mathrm{C}$. The antiinsulin antibody was incubated for $2 \mathrm{~h}$ at room temperature.

Secondary antibodies conjugated to fluorescein isothiocyanate, Cy3, or Cy5 were diluted to 1:100 (Jackson ImmunoResearch, West Grove, PA). All slides were cover 
Table 1 Characteristics of subjects

\begin{tabular}{|c|c|c|c|c|c|c|}
\hline Number & Sex & Age (yrs) & BMI $\left(\mathrm{kg} / \mathrm{m}^{2}\right)$ & Duration of diabetes (yrs) & FPG (mg/dl) & Cause of death \\
\hline \multicolumn{7}{|c|}{ Non-diabetics } \\
\hline 1 & M & 40 & 17.6 & - & 89 & Pneumonia \\
\hline 2 & $\mathrm{~F}$ & 20 & 20.2 & - & 97 & Congenital heart anomalies \\
\hline 3 & $\mathrm{~F}$ & 46 & 25.8 & - & 99 & Acute hepatic insufficiency \\
\hline 4 & M & 37 & 21.8 & - & 98 & $\mathrm{~T}$ cell lymphoma \\
\hline 5 & $\mathrm{~F}$ & 46 & 15.4 & - & 83 & Breast cancer, pneumonia \\
\hline $6^{\mathrm{a}}$ & $\mathrm{M}$ & 53 & 24.2 & - & NA & Gastric cancer \\
\hline $7^{\mathrm{a}}$ & $\mathrm{F}$ & 21 & 19.9 & - & NA & Empyema \\
\hline \multicolumn{7}{|l|}{$\mathrm{T} 2 \mathrm{DM}$} \\
\hline 8 & $\mathrm{~F}$ & 49 & 46.9 & 5 & 119 & Acute pulmonary embolism \\
\hline 9 & M & 65 & 34.6 & Unknown & 188 & Sepsis \\
\hline 10 & $\mathrm{~F}$ & 62 & 44.7 & 7 & 121 & Pneumonia \\
\hline 11 & M & 63 & 33.4 & 5 & 161 & Bacterial pericarditis \\
\hline 12 & $\mathrm{~F}$ & 78 & 30.7 & 15 & 116 & Congestive heart failure \\
\hline \multicolumn{7}{|c|}{ Recent onset T1DM } \\
\hline $13^{\mathrm{b}}$ & M & 89 & 18.0 & 3 months & 349 & - \\
\hline 14 & $\mathrm{~F}$ & 14 & 13.8 & 2 weeks & 530 & Diabetic ketoacidosis \\
\hline 15 & $\mathrm{~F}$ & 36 & 25.9 & Days & 10 (4 days prior to death) & Diabetic ketoacidosis \\
\hline 16 & $\mathrm{~F}$ & 22 & 20.9 & 1 week & 504 & Diabetic ketoacidosis \\
\hline \multicolumn{7}{|c|}{ Long standing T1DM } \\
\hline 17 & M & 35 & 18.7 & 23 & 220 & Pneumonia \\
\hline 18 & $\mathrm{~F}$ & 38 & 21.1 & 25 & 253 & Cerebral hemorrhage \\
\hline 19 & $\mathrm{~F}$ & 40 & 34.7 & 23 & 462 & Retroperitoneal hemorrhage \\
\hline 20 & $\mathrm{~F}$ & 49 & 19.3 & 32 & 187 & Acute myocardial infarction \\
\hline 21 & $\mathrm{~F}$ & 51 & 17.4 & 39 & 273 & Acute adrenal insufficiency \\
\hline 22 & $\mathrm{~F}$ & 54 & 18.1 & 45 & 243 & Pulmonary embolism \\
\hline
\end{tabular}

${ }^{a}$ Pancreas head, all other cases are tail

b Surgically removed tissue

FPG, fasting plasma glucose

NA, not available

Table 2 List of primary antibodies

\begin{tabular}{lllcc}
\hline Antigen & Code & Company & Dilution & Species \\
\hline VMAT2 & AB1767 & Millipore, Temecula, CA & $1: 200$ & Rabbit, polyclonal \\
VMAT2 & AHP1123 & AbD Serotec, Oxford, UK & $1: 200$ & Goat, polyclonal \\
Insulin & $18-0067$ & Invitrogen, Carlsbad, CA & $1: 100$ & Guinea pig, polyclonal \\
Glucagon & G2654 & Sigma, St. Louis, MO & $1: 1,000$ & Mouse, monoclonal \\
Somatostatin & MAB354 & Millipore & $1: 50$ & Rat, monoclonal \\
Pancreatic polypeptide & NB100-1793 & Novus Biologicals, Littleton, CO & $1: 150$ & Goat, polyclonal \\
Pancreatic polypeptide & $18-0043$ & Invitrogen & $1: 100$ & Rabbit, polyclonal \\
Neuronal nuclei (NeuN) & MAB377 & Millipore & $1: 100$ & Mouse, monoclonal \\
Neuron-specific class III $\beta$-tubulin (TuJ-1) & MO15013 & Neuromics, Edina, MN & $1: 100$ & Mouse, monoclonal \\
Tyrosine hydroxylase & MAB318 & Millipore & $1: 100$ & Mouse, monoclonal \\
\hline
\end{tabular}

slipped with Vectashield-DAPI mounting medium (Vector Laboratories), stored in the dark at $4^{\circ} \mathrm{C}$, and analyzed within 1-3 days after staining.
To assure specificity of antibody detection of VMAT2, both a rabbit polyclonal anti-VMAT2 (Millipore) and a goat polyclonal anti-VMAT2 (AbD Serotec) were used 
(Table 2), side by side, in the immunofluorescence protocol. The same pattern of VMAT2 staining was observed with both primary antibodies in human pancreatic tissue (Supplementary Fig. 1a, b). We subsequently used the rabbit polyclonal anti-VMAT2 antibody in this study. In addition, to confirm the specificity of VMAT2 staining, the rabbit polyclonal anti-VMAT2 antibody was preincubated for $2 \mathrm{~h}$ with 10 or 100 excess of VMAT2 blocking peptide (AG263, Millipore) or diluted with PBS. Blockage of antibody was confirmed by immunohistochemistry in adjacent sections of human pancreas (Supplementary Fig. 1a, c, d).

\section{Morphometric analysis}

Fluorescent slides were viewed using a Leica DM6000 microscope (Leica Microsystems, Wetzlar, Germany) and images were acquired using Openlab software (Improvision, Waltham, MA).

To measure the pancreatic fractional beta cell and VMAT2 area, a montage of the whole pancreatic section imaged at $\times 50$ magnification $(\times 5$ objective $)$ was created using Openlab (Improvision) and ImageJ (National Institutes of Health, Bethesda, MD) software on a Leica DM6000. The ratio of the beta cell area or VMAT2 area to pancreas area was digitally quantified using Image Pro Plus software (Media Cybernetics, Silver Springs, MD, USA) as previously described (Meier et al. 2005, 2006).

The islets in each case were also analyzed at a higher magnification $(20 \times$ objective). At least 20 islets (with a minimum of 4 beta cells per islet in plane of section) were selected at random in each case. Scattered beta cells were defined as a cluster of less than 4 beta cells in the same section.

\section{Confocal microscopy}

The co-localization of VMAT2 and insulin or pancreatic polypeptide was confirmed by use of a Leica spinning-disc laser confocal microscope (DMIRE2; Leica) and images were acquired using Velocity software (Improvision). The series ( $\mathrm{z}$ ) sections were acquired with a $0.5 \mu \mathrm{m}$ step size.
Fig. 1 Insulin and VMAT2 staining in a representative pancreas from a non-diabetic subject (a and $\mathbf{b}$ ) and subject with long standing type 1 diabetes (c and d). Insulin, green; VMAT2, red; DAPI (nucleus), blue. Insulin and VMAT2 was abundantly present in the pancreas of non-diabetic control, but much less abundant in the subject with long standing type 1 diabetes. Original magnification: $5 \times$. Scale bars $=1 \mathrm{~mm}$
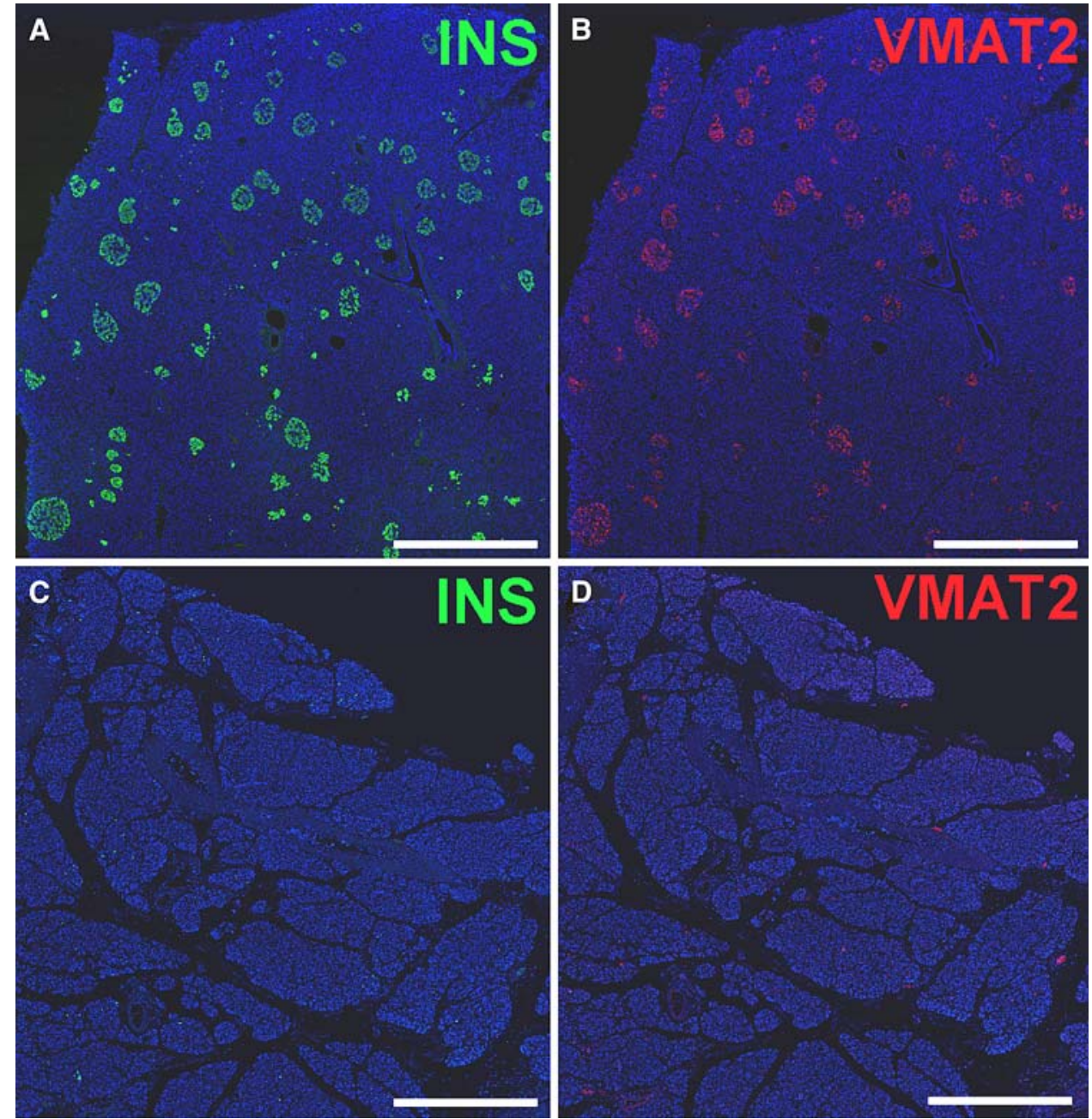
Statistical analysis

Data are presented as mean \pm SEM. Statistical comparison was carried out using the Student's $t$ test or one-way ANOVA followed by Bonferroni's post hoc correction. A simple regression analysis was used to test the correlation between beta cell area and VMAT2 area. A $P$ value $<0.05$ was considered statistically significant.

\section{Results}

VMAT2 expression in non-diabetic human pancreas

VMAT2 expression was abundant in pancreas of non-diabetic subjects and its distribution overlapped substantially with insulin expression (Figs. 1a, b, 2a-c). Co-localization of insulin and VMAT2 expression was confirmed by confocal microscopy (Fig. 3). Most $(88 \pm 4 \%)$ beta cells (defined as insulin staining) were also positive for VMAT2. However, VMAT2 negative beta cells were invariably present in each case.

The proportion of beta cells scattered in exocrine tissue remote from islets that were positive for VMAT2 was lower than beta cells within islets $(29 \pm 15 \%$ vs. $88 \pm 4 \%$ of beta cells, $P<0.05$ ). Insulin positive cells with exocrine ducts were also less frequently positive for VMAT2 than beta cells in islets $(39 \pm 7 \%$ vs. $88 \pm 4 \%, P<0.05)$.

VMAT2 positive-insulin negative cells were also occasionally seen within many islets $(1.7 \pm 0.3$ cells per islet cross section, Fig. 3). To further evaluate the nature of these cells, we examined islets for VMAT2 double staining vs. glucagon, somatostatin and pancreatic polypeptide (PP). There was no co-localization of glucagon and
Fig. 2 Immuno-fluorescent staining of representative islets from a non-diabetic subject for insulin (a, green), VMAT2 (b, red) and insulin, VMAT2 and nucleus using DAPI (blue) merged (c). Most, but not all, insulin staining cells are also VMAT2 positive (yellow to orange cells in c). VMAT2 staining was mostly confined to the islet. For comparison immuno-fluorescence with same colors merged is shown in type 2 diabetes (d), recent onset type 1 diabetes (r-T1D, e) and long standing type 1 diabetes (1-T1D, f). A similar pattern of the VMAT2 staining was seen in the subjects with diabetes with most, but not all, beta cells positive for VMAT2 and minimal VMAT2 staining outside the islet. (f) Few beta cells were seen in the islet (indicated by arrows) of long standing type 1 diabetic subjects. VMAT2 positive beta cells are indicated by arrow heads. Original magnification: $20 \times$. Scale bars $=30 \mu \mathrm{m}$
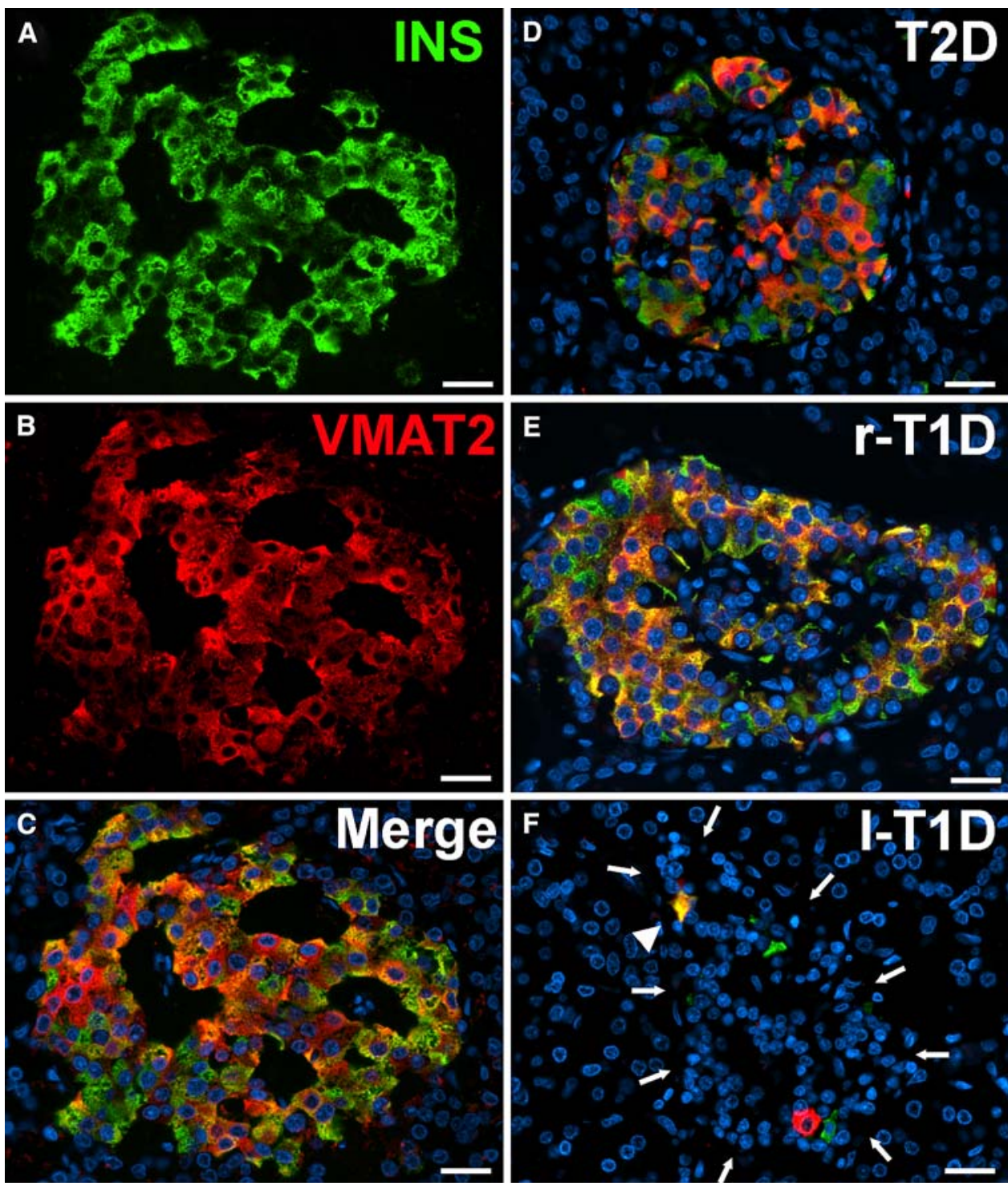

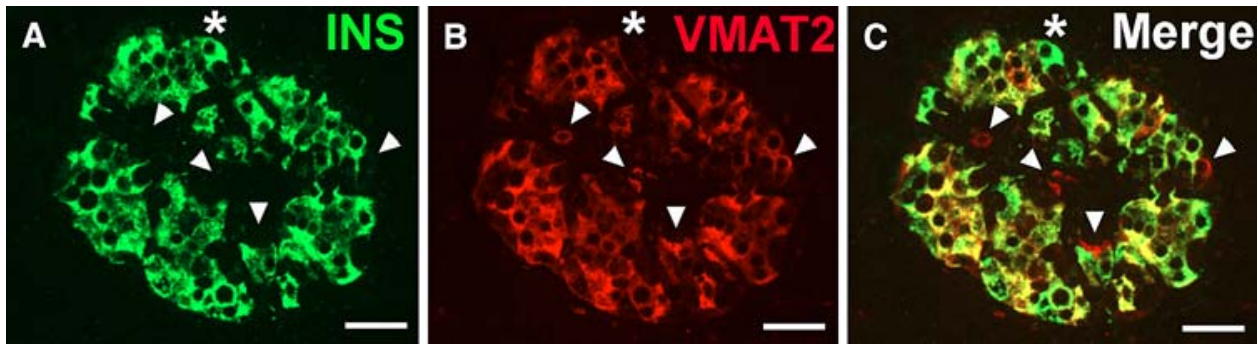

Fig. 3 Confocal image of a representative islet. Insulin, green; VMAT2, red. Confocal microscopy confirmed the co-localization of VMAT2 and insulin $(\mathbf{a}-\mathbf{c})$. It is noted that insulin positive but VMAT2 negative cells (indicated by asterisk) and VMAT2 positive but insulin negative cells (indicated by arrow heads) were seen within the islets. Original magnification: $20 \times$. Scale bars $=30 \mu \mathrm{m}$. Images are from a recent onset T1DM case
Fig. 4 Double staining of VMAT2 and glucagon $(\mathbf{a}-\mathbf{c})$, somatostatin $(\mathbf{d}-\mathbf{f})$ or pancreatic polypeptide (PP) (g-i). Glucagon, somatostatin or PP, green; VMAT2, red; DAPI (nucleus), blue. VMAT2 expression was co-localized with neither glucagon $(\mathbf{a}-\mathbf{c})$ nor somatostatin $(\mathbf{d}-\mathbf{f})$. However, VMAT2 positive PP cells were abundantly seen in pancreas head "PP rich" lobe $(\mathbf{g}-\mathbf{i})$. Original magnification: $20 \times$ Scale bars $=50 \mu \mathrm{m}$. $\mathbf{a}-\mathbf{f}$, images are from a recent onset T1DM case; $\mathbf{g}-\mathbf{i}$, non-diabetic case
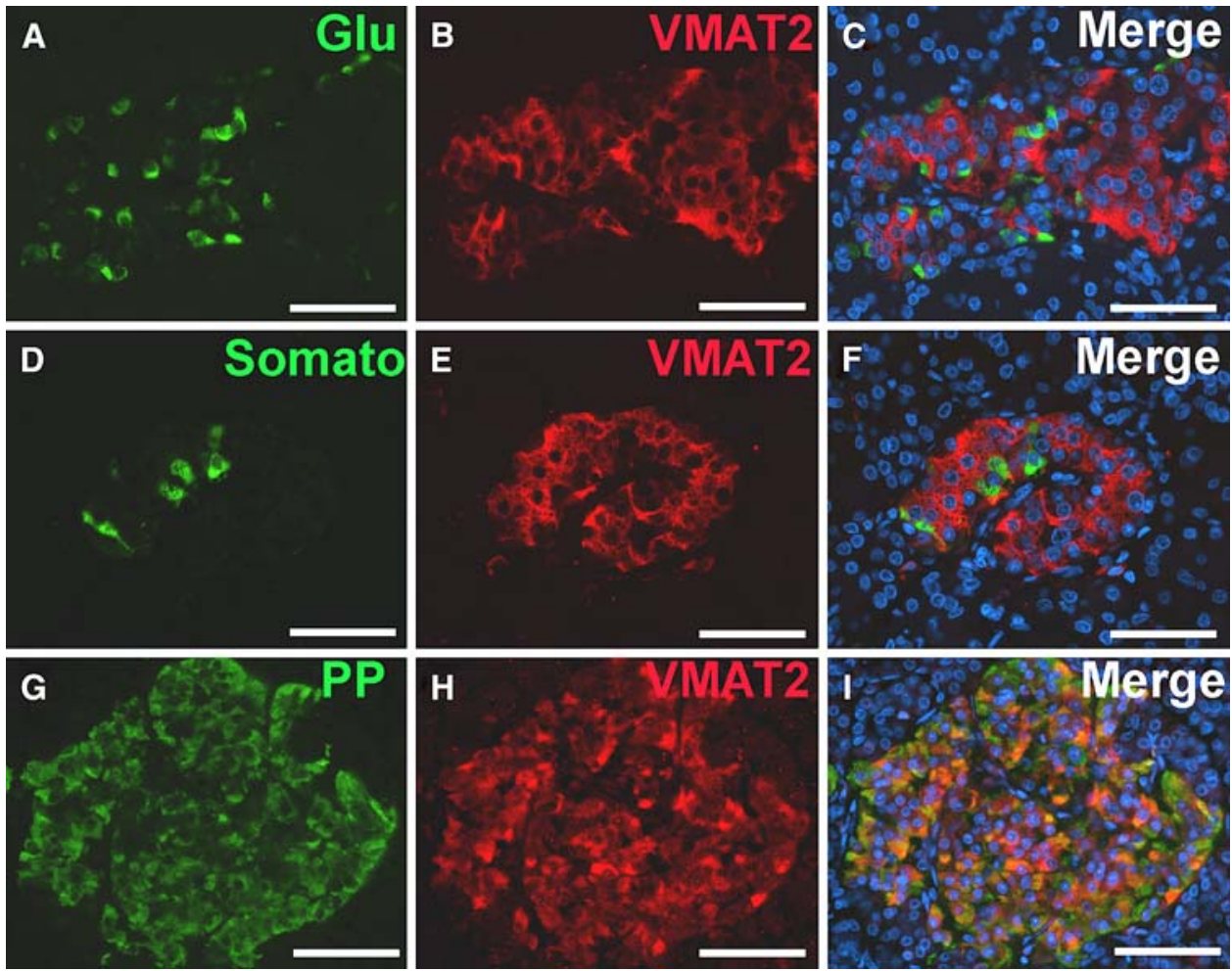

VMAT2 (Fig. 4a-c). Most of somatostatin positive cells were also negative for VMAT2 (Fig. 4d-f), but a few somatostatin positive cells $(0-4 \%$ of the cells) were positive for VMAT2 (data not shown).

However, $39 \pm 7 \%$ of islet PP positive cells also expressed VMAT2 (Figs. 4g-i, 5). Co-localization of PP and VMAT2 was confirmed by confocal microscopy (Fig. 5a-c). VMAT2 positive PP cells were more frequent in scattered groups of PP cells in the exocrine pancreas compared to the PP cells within islets. As expected PP cells were most abundant in the head of the pancreas where VMAT2 positive PP cells were therefore also most frequent ( $\sim 70 \%$ of PP cells) (Fig. $4 \mathrm{~g}-\mathrm{i}$ ). Triple staining for $\mathrm{PP}$, insulin and VMAT2 revealed that most of the VMAT2 positive-insulin negative cells could be accounted for as PP cells (Fig. 5d-g). Only $\sim 1 \%$ of VMAT2 positive cells were negative for both insulin and PP (Fig. 5g), and were most likely mast cells or possibly nerve cells (Fig. 6). We detected no co-localization of PP and insulin (Fig. 5).

\section{VMAT2 expression in T2DM, T1DM recent and long standing}

The overall pattern of pancreatic VMAT2 expression was comparable in type 1 and 2 diabetic subjects (Fig. 2d-f). VMAT2 expression was, for the most part, co-localized with insulin positive cells to the extent these were present. As in non-diabetic subjects, most, but not all, beta cells were also positive for VMAT2 $(81 \pm 4 \%$ and $72 \pm 12 \%$ of beta cells in subjects with T2DM and T1DM, 
Fig. 5 (a-c) Confocal image of a representative islet. PP, green; VMAT2, red. Confocal microscopy confirmed the colocalization of VMAT2 and PP (a-c, indicated by arrowheads). In tail of the pancreas $\sim 40 \%$ of PP cells were positive for VMAT2. d-g) Triple staining for PP (green, d), insulin (blue, e), VMAT2 (red, f) and merged image (g). VMAT2 positive beta cells are seen as purple cells in $\mathbf{g}$. Triple staining revealed that the VMAT2 positive but insulin negative cells were PP cells (g, yellow cells indicated by arrows), although VMAT2 positive but both insulin and PP negative cells were still seen occasionally (g, indicated by arrowhead), which are likely mast cells or neuron cells. Original magnification: $20 \times$. Scale bars $=15(\mathbf{a}-\mathbf{c})$ or $30 \mu \mathrm{m}(\mathbf{d}-$ g). Images are from a recent onset T1DM case
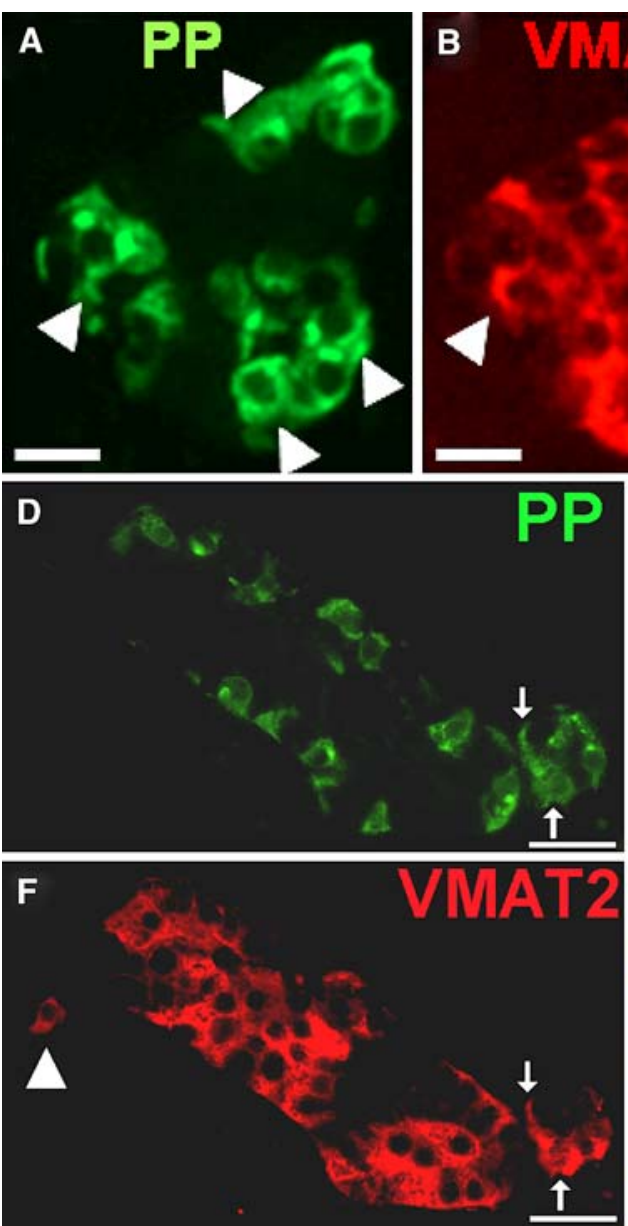
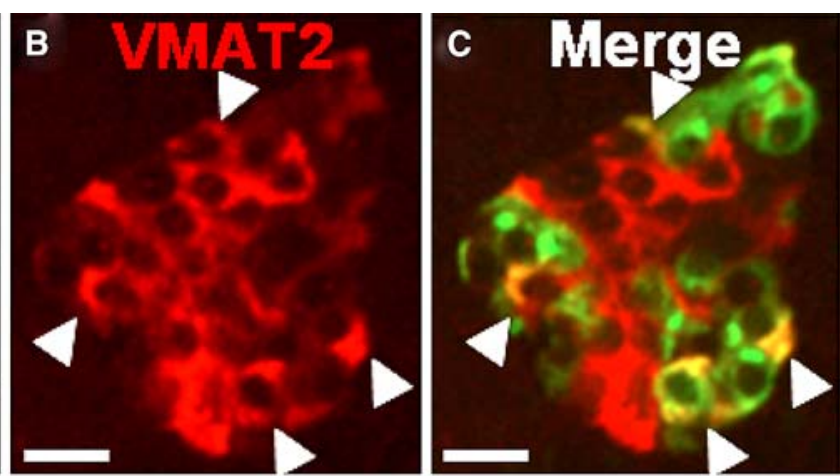

E

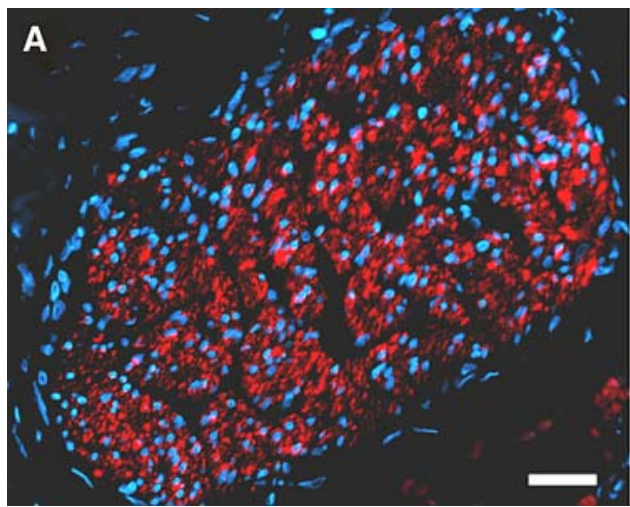

Fig. 6 (a) Bundle of VMAT2 positive nerve fibers surrounded by connective tissue in the pancreas. VMAT2, red; DAPI (nucleus), blue. (b) VMAT2 positive nerve fibers (arrowhead), but not VMAT2 positive cells (asterisks) were co-stained with neuron marker (green).

respectively). As in non-diabetic subjects, beta cells scattered in exocrine tissue were less often VMAT2 positive than beta cells in islets $(37 \pm 5 \%$ vs. $81 \pm 4 \%, P<0.01$ in T2DM, $30 \pm 18 \%$ vs. $72 \pm 12 \%, P=0.1$ in subjects with $\operatorname{T1DM}(n=4))$.

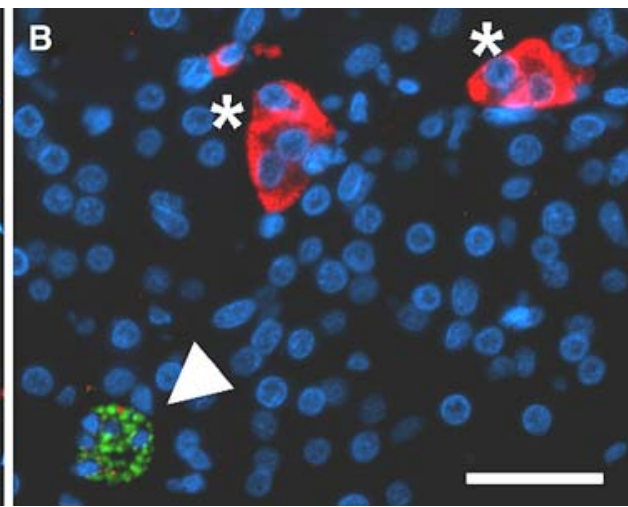

Neuron marker (NeuN and Tuj-1), green; VMAT2, red; DAPI (nucleus), blue. Original magnification: $20 \times$. Scale bars $=30 \mu \mathrm{m}$. Images are from a recent onset T1DM case

Relationship between VMAT2 and insulin pancreatic fractional area in all groups

Consistent with co-localization of insulin and VMAT2, the fractional pancreatic (tail) insulin and VMAT2 positive 


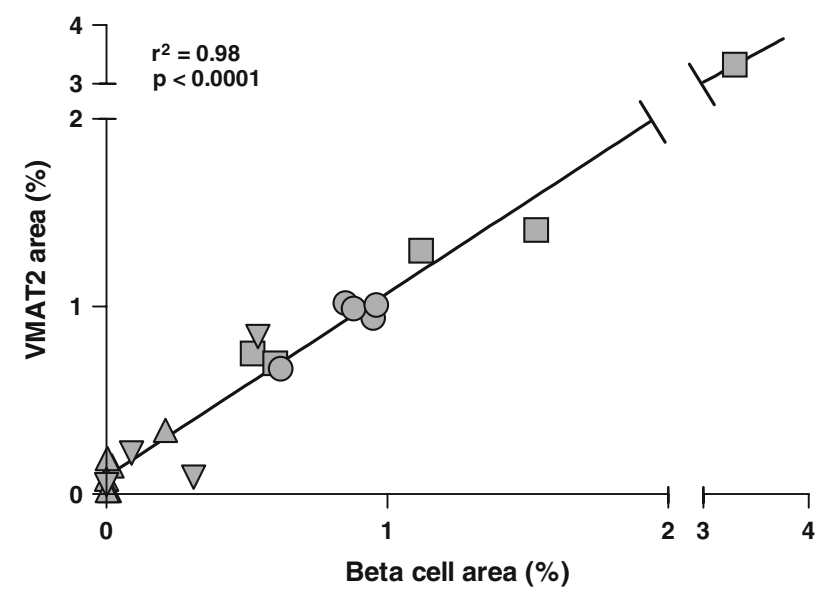

Fig. 7 Correlation between fractional pancreas beta cell vs. VMAT2 positive area in tail of pancreas. There was a close correlation between fractional beta cell and VMAT2 positive area. However, the regression line does not run through the zero-point $(y=x+0.1)$. Square, non-diabetics; circle, type 2 diabetes; reverse triangle, recent onset type 1 diabetes; triangle, long standing type 1 diabetes

area were comparably decreased in the subjects with diabetes (Figs. 1c, d, 7). The fractional (tail) pancreatic VMAT2 positive area was slightly greater than the corresponding beta cell fractional area when all cases (nondiabetic, T1DM, T2DM) were included $(0.71 \pm 0.17 \%$ vs. $0.63 \pm 0.17 \%, P<0.01)$, the excess VMAT2 fractional area (VMAT2 fractional area-beta cell fractional area) was comparable in each group $(0.08 \pm 0.06 \%$, $0.08 \pm 0.03 \%, 0.06 \pm 0.11 \%$ and $0.09 \pm 0.03 \%$ in nondiabetics, T2DM, recent onset T1DM and long standing T1DM, respectively, $P=0.9$ ). As a result, in the tail of the pancreas the pancreatic VMAT2 fractional area was strongly correlated with pancreatic beta cell fractional area $\left(r^{2}=0.98\right)$ described by the equation;

VMAT2 positive area $(\%)=$ beta cell area $(\%)+0.1$.

\section{Discussion}

Our overall objective in this study was to establish the relationship between VMAT2 and insulin expression in human pancreas, and in particular to establish if this relationship is disturbed in either type 1 or type 2 diabetes.

We report that there is excellent overlap between VMAT2 and insulin expression in the tail of the human pancreas, and that this relationship is not altered in either patients with type 1 or type 2 diabetes. However,we also report that approximately $40 \%$ of PP cells also express VMAT2. PP cells are most abundant in the head of the pancreas, a region of pancreas that we did not have access to in most cases. However, uptake of the radio-ligand [11C]DTBZ by via VMAT2 in human pancreas presumably reflects the whole pancreas, including the PP enriched head of pancreas. From our data one would predict that there would be residual [11C]DTBZ uptake in pancreas of patients with even long standing T1DM with minimal beta cell mass. This is indeed the finding in clinical studies (Freeby et al. 2007; Liu et al. 2007). With this insight it will be of interest to seek to establish methods that might permit measurement of VMAT2 uptake selectively in the tail of the pancreas.

In one prior study of human pancreas VMAT2 and PP were not reported to be co-localized (Anlauf et al. 2003). The reason for the difference between that study and our present report is not clear, but perhaps may relate to the relatively low frequency of PP cells in the tail and body of the pancreas. The co-localization of VMAT2 to a proportion of PP cells became most obvious in the head of the pancreas where PP cells are most abundant. To confirm this finding we reproduced the co-localization of VMAT2 and PP using different primary antibodies for both proteins (Table 2). Moreover, in the prior human study 5 of 8 nonfunctioning well-differentiated pancreatic endocrine tumors with PP immunophenotype (among them only one tumor coincided with insulin immunophenotype) were VMAT2 positive (Anlauf et al. 2003).

A previously unnoted finding reported here is that approximately $10 \%$ of pancreatic beta cells in islets are VMAT2 negative while this proportion increases to $\sim 70 \%$ in beta cells scattered in the exocrine tissue remote from pancreatic islets, a pattern that was comparable in both non-diabetic cases and those with T1DM and T2DM. It is unknown whether beta cells that express VMAT2 are functionally distinct from those that do not, or what the basis of this difference is. While the function of VMAT2 expression by beta cells is unknown, monoamines taken up by VMAT2 such as histamine, norepinephrine, dopamine and serotonin have been reported to modulate beta cell function (Ahren 2000; Brunicardi et al. 1995).

One possible explanation for our detection of VMAT2 staining in some but not all beta cells is that the subcellular localization of VMAT2 is polar in which case beta cells may appear negative for VMAT2 if the cellular pole enriched in VMAT2 expression is out of the plane of section. To address this possibility we used confocal imaging which affirmed that there are two distinct populations of pancreatic beta cells that either do or do not express VMAT2. Moreover VMAT2 positive and VMAT2 negative monoaminergic neuron cells have been reported in the central nervous system (Eiden 2000; Weihe and Eiden 2000). While Anlauf et al. reported that all beta cells expressed VMAT2 in nonneoplastic human pancreas, in the same study VMAT2 positive cells were detected in only 10 of 34 benign insulinomas and 5 of 10 malignant insulinomas (Anlauf et al. 2003), consistent with the heterogeneity of VMAT2 expression in beta cells observed here. 
In conclusion, we report a close linear correlation between insulin and VMAT2 immunostaining in the tail of pancreas in humans with and without diabetes. Although this result supports the concept of non-invasive measurement of beta cell mass in humans by using [11C]DTBZ and PET, caution will be needed to interpret the results because of VMAT2 expression in PP cells as well as heterogenous VMAT2 expression among beta cells.

Acknowledgments This study was supported by funding from the NIH (DK059579), the Larry L. Hillblom Foundation and the Manpei Suzuki Diabetes Foundation. We are grateful to our colleagues in the Larry Hillblom Islet Research Center for their excellent suggestions.

Open Access This article is distributed under the terms of the Creative Commons Attribution Noncommercial License which permits any noncommercial use, distribution, and reproduction in any medium, provided the original author(s) and source are credited.

\section{References}

Ahren B (2000) Autonomic regulation of islet hormone secretionimplications for health and disease. Diabetologia 43:393-410. doi: $10.1007 / \mathrm{s} 001250051322$

Anlauf M, Eissele R, Schafer MK, Eiden LE, Arnold R, Pauser U et al (2003) Expression of the two isoforms of the vesicular monoamine transporter (VMAT1 and VMAT2) in the endocrine pancreas and pancreatic endocrine tumors. J Histochem Cytochem 51:1027-1040

Anlauf M, Schafer MK, Schwark T, von Wurmb-Schwark N, Brand V, Sipos B et al (2006) Vesicular monoamine transporter 2 (VMAT2) expression in hematopoietic cells and in patients with systemic mastocytosis. J Histochem Cytochem 54:201-213. doi: 10.1369/jhc.5A6739.2005

Brunicardi FC, Shavelle DM, Andersen DK (1995) Neural regulation of the endocrine pancreas. Int J Pancreatol 18:177-195

Butler AE, Janson J, Bonner-Weir S, Ritzel R, Rizza RA, Butler PC (2003) Beta-cell deficit and increased beta-cell apoptosis in humans with type 2 diabetes. Diabetes 52:102-110. doi: 10.2337/diabetes.52.1.102

Butler AE, Galasso R, Meier JJ, Basu R, Rizza RA, Butler PC (2007) Modestly increased beta cell apoptosis but no increased beta cell replication in recent-onset type 1 diabetic patients who died of diabetic ketoacidosis. Diabetologia 50:2323-2331. doi: 10.1007/s00125-007-0794-x

Eiden LE (2000) The vesicular neurotransmitter transporters: current perspectives and future prospects. FASEB J 14:2396-2400. doi: 10.1096/fj.00-0817rev

Erickson JD, Schafer MK, Bonner TI, Eiden LE, Weihe E (1996) Distinct pharmacological properties and distribution in neurons and endocrine cells of two isoforms of the human vesicular monoamine transporter. Proc Natl Acad Sci USA 93:5166-5171. doi:10.1073/pnas.93.10.5166

Freeby M, Simpson N, Saxena C, Dashnaw S, Hirsch J, Prince M et al (2007) Non-invasive pancreatic beta cell imaging using 11C dihydrotetrabenazine and positron emission tomography. Diabetes 56:A84 (Abstract)

Frey KA, Koeppe RA, Kilbourn MR (2001) Imaging the vesicular monoamine transporter. Adv Neurol 86:237-247

Liu EH, Herscovitch P, Barker C, Channing M, Geras-Raaka E, Pechihold K et al (2007) 11C-DTBZ PET scanning: its potential for measuring beta cell mass in vivo. Diabetes 56:A83 (Abstract)

Maffei A, Liu Z, Witkowski P, Moschella F, Del Pozzo G, Liu E et al (2004) Identification of tissue-restricted transcripts in human islets. Endocrinology 145:4513-4521. doi:10.1210/en.2004-0691

Meier JJ, Bhushan A, Butler AE, Rizza RA, Butler PC (2005) Sustained beta cell apoptosis in patients with long-standing type 1 diabetes: indirect evidence for islet regeneration? Diabetologia 48:2221-2228. doi:10.1007/s00125-005-1949-2

Meier JJ, Lin JC, Butler AE, Galasso R, Martinez DS, Butler PC (2006) Direct evidence of attempted beta cell regeneration in an 89-year-old patient with recent-onset type 1 diabetes. Diabetologia 49:1838-1844. doi:10.1007/s00125-006-0308-2

Ritzel RA, Butler AE, Rizza RA, Veldhuis JD, Butler PC (2006) Relationship between beta-cell mass and fasting blood glucose concentration in humans. Diabetes Care 29:717-718. doi: 10.2337/diacare.29.03.06.dc05-1538

Simpson NR, Souza F, Witkowski P, Maffei A, Raffo A, Herron A et al (2006) Visualizing pancreatic beta-cell mass with [11C]DTBZ. Nucl Med Biol 33:855-864. doi:10.1016/j.nucme dbio.2006.07.002

Souza F, Simpson N, Raffo A, Saxena C, Maffei A, Hardy M et al (2006) Longitudinal noninvasive PET-based beta cell mass estimates in a spontaneous diabetes rat model. J Clin Invest 116:1506-1513. doi:10.1172/JCI27645

Weihe E, Eiden LE (2000) Chemical neuroanatomy of the vesicular amine transporters. FASEB J 14:2435-2449. doi:10.1096/ fj.00-0202rev

Weihe E, Schafer MK, Erickson JD, Eiden LE (1994) Localization of vesicular monoamine transporter isoforms (VMAT1 and VMAT2) to endocrine cells and neurons in rat. J Mol Neurosci 5:149-164. doi:10.1007/BF02736730 